\title{
НАУЧНАЯ ЖИЗНЬ
}

DOI: $10.18384 / 2310-6794-2019-3-149-155$

\section{АНОНС ЕЖЕГОДНОГО ДОКЛАДА ЦЕНТРА ИССЛЕДОВАНИЙ ПРОБЛЕМ ТЕРРИТОРИАЛЬНОГО УПРАВЛЕНИЯ И САМОУПРАВЛЕНИЯ МОСКОВСКОГО ГОСУДАРСТВЕННОГО ОБЛАСТНОГО УНИВЕРСИТЕТА ЗА 2019 ГОД}

\section{Балытников В. В., Глухов В. В., Михайлов Е. Н., Сергеев А. А., Чертков А. Н., Штукин В. В.}

Московский государственный областной университет

141014, Московская обл., г. Мытищи, ул. Веры Волошиной, д. 24,

Российская Федерация

\section{ANNOUNCEMENT OF 2019 ANNUAL REPORT OF THE CENTRE FOR INVESTIGATION OF TERRITORIAL GOVERNIMENT AND SELF-GOVERNMENT ISSUES OF MOSCOW REGION STATE UNIVERSITY}

\section{Balytnikov, V. Glukhov, E. Mikhailov, A. Sergeev, A. Chertkov, V. Shtukin Moscow Region State University 24 Very Voloshinoi ul., Mytishchi 141014, Moscow Region, Russian Federation}

Созданный весной 2019 года в Московском государственном областном университете Центр исследований проблем территориального управления и самоуправления осенью этого года представит свой первый ежегодный доклад о проблемных вопросах и перспективных направлениях развития правового регулирования и правоприменительной практики в соответствующих сферах социальной деятельности.

Темой доклада станет актуальный отечественный и зарубежный опыт разграничения компетенции между региональным и муниципальным уровнем власти.

Текст доклада будет выпущен отдельным изданием, а его электронная версия - размещена на сайте Центра 
в целях максимально широкого распространения среди должностных лиц регионального и муниципального уровня, научных и практически работников в области государственного и муниципального управления, конституционного, административного и муниципального права, государственных и муниципальных служащих, общественных активистов, всех интересующихся проблематикой территориального управления и самоуправления.

Ниже вниманию уважаемых читателей предлагается краткое тезисное изложение содержания ряда идей основных разделов доклада:

\section{Раздел 1. Сервисная природа территориального управления и самоуправления}

Основное назначение данного блока - обоснование идеи принципиального сущностного единства региональной и местной публичной власти, основанной на задаче служения населению в сфере исполнения полномочий субфедерального (в широком понимании) уровня. Природа этих полномочий также, по сути, едина.

С политико-правовой точки зрения в данном случае необходимо говорить о том, что все полномочия публичной власти, осуществляемые ниже общегосударственного уровня, имеют общий сервисный характер удовлетворения нужд и защиты интересов граждан на региональном и местном уровнях.

С чисто юридической точки зрения в подкрепление такого рода рассуждений можно привести значительное количество правовых позиций Европейского Суда по правам человека (ЕСПЧ), а также немалое число правовых позиций других международных и национальных судебных органов (в т.ч. Конституционного Суда Российской Федерации). Так, ЕСПЧ в своих решениях неоднократно подчёркивал, что местные власти входят в систему государственного управления и неотделимы от системы государственной власти в широком её понимании. Конституционный Суд Российской Федерации в своих решения отмечал, что местное самоуправление по самой своей природе основано на сочетании государственных и общественных начал, а вытекающие из законодательных норм публичные обязанности по обеспечению нужд и защите интересов по своей природе как таковые зачатую не являются ни полномочиями органов государственной власти, ни полномочиями органов местного самоуправления, но относятся к региональной или муниципальной компетенции в соответствии с усмотрением законодателя.

С прагматической точки зрения этот вывод подкрепляется анализом установленных в Российской Федерации и в других странах критериев эффективности региональной и местной власти.

В целом же сервисная модель территориального управления и самоуправления означает реальное предпочтение блага граждан перед процессами излишней политизации указанных сфер.

\section{Раздел 2.}

Отечественные подходы в области разграничения полномочий между региональными и муниципальными уровнями публичной власти

В новейшей истории России можно выделить, по меньшей мере, четыре 
модели разграничения предметов ведения и полномочий региональной государственной власти и муниципальной власти.

1) модель по Закону РСФСР от 6 июня 1991 № 1550-1 «О местном самоуправлении в Российской Федерации»;

2) модель по Федеральному закону от 28 августа 1995 № 154-Ф3 «Об общих принципах организации местного самоуправления в Российской Федерации» (далее также - «Федеральный закон №154-Ф3»);

3) модель по Федеральному закону от 06.10.2003 № 131-Ф3 «Об общих принципах организации местного самоуправления в Российской Федерации» (далее также «Федеральный закон № 131-Ф3»);

4) Современная модель, возникшая и развивающаяся на основе изменений, вносимых начиная с средины текущего десятилетия в Федеральный закон № 131-Ф3, а также в федеральный закон от 6 октября 1999 г. № 184-Ф3 «Об общих принципах организации законодательных (представительных) и исполнительных органов государственной власти субъектов Российской Федерации».

Ряд принципиальных положений современной модели вызывают определённую (и в некоторой своей части обоснованную) обеспокоенность в экспертном сообществе. Однако представляется, что в данном случае устоявшиеся догмы и стереотипы не должны возобладать над практическими соображениями общественной пользы. Главным критерием в оценке тех или иных новелл, на взгляд авторов доклада, должна быть эффективность решения задач публичной власти с позиций интересов граждан.
Реализация указанных новелл наглядно отражена в судебной практике последних лет. Эта практика, с одной стороны, уже сложилась, является достаточно обширной и показывает наиболее острые проблемы, вызывающие споры при правоприменении. С другой стороны, многие выводы судебных инстанций, по всей видимости, пока нельзя назвать окончательными, и тем более вполне обоснованными Формирование взвешенного и сбалансированного общего массива решений и правовых позиций судов и иных правоприменительных органов, участвующих в разрешении споров, возникающих вокруг разграничения компетенции региональных и муниципальных органов, несомненно, будет продолжаться. В докладе Центра будут предложены новые правовые аргументы и даны вытекающие из них рекомендации, которые, на взгляд их авторов, позволят направить соответствующие процессы в наиболее конструктивное русло.

\section{Раздел 3.}

\section{Перераспределение полномочий между органами власти регионального и муниципального уровней}

Исследования более чем 25-летнего опыта реализации современной конституционной модели федерализма и местного самоуправления позволяют констатировать наличие следующих проблем:

- гипертрофированное восприятие самостоятельности местного самоуправления и его структурного отделения от системы органов государства привело к невыполнению многих обя- 
зательств публичной власти перед населением.

- гармонизация компетенции с ресурсными возможностями не была достигнута в полной мере (для оперативного реагирования на «выравнивание» ситуации не хватало правовых средств, а для профицитного бюджетного обеспечения всех уровней публичной власти - материальных средств).

- разграничение компетенции между региональным и муниципальным уровнями осуществления публичной власти часто выстраивалось на приверженности той или иной доктрине при недостаточном учёте конкретных нужд населения.

- часть вопросов местного значения не была, не могла и не может быть решена без участия регионов.

В 2014 году федеральные законы № 131-Ф3 и № 184-Ф3 были дополнены механизмом перераспределения полномочий между органами местного самоуправления и органами государственной власти субъекта Российской Федерации путём принятия регионального закона на срок не менее срока полномочий регионального органа законодательной власти. С 2016 года сфера действия данного механизма был ограничена лишь случаями, установленными федеральными законами.

Целый ряд субъектов Российской Федерации воспользовались соответствующими инструментами. В числе регионов, достигших на этом пути наилучших результатов, следует особо отметить Московскую область. К её органам исполнительной власти перешли 25 полномочий органов местного самоуправления. Благодаря комплексному применению указанного механизма в Московской области, было, в частности, достигнуто масштабное повышение эффективности регулирования вопросов территориального планирования, землепользования, строительства, и т.д. Так, с 2014 по 2018 гг. доля утверждённых генеральных планов в целом по области выросла с 39 до 97 процентов, число утверждённых правил землепользования и застройки возросло с 22 до 100 процентов, а тянувшийся до этого более двух десятилетий процесс формирования актуальных современных схем водоснабжения, водопотребления и водоотведения в городах и других крупных населённых пунктах области был полностью завершён менее чем за пять лет.

При этом на стыке теоретических построений и практических решений - выявляется целый блок проблем в области перераспределения полномочий между региональным и местным уровнями осуществления публичной власти, в том числе:

1. Проблемы ценностно-правовых основ перераспределения полномочий публичной власти. К этим основам относятся:

1.1. Принципиальное сущностное единство публичной власти, а следовательно - её компетенции.

1.2. Максимально эффективное обеспечение прав и свобод человека, как основная цель и смыслообразующая категория осуществления публичной власти на всех уровнях.

1.3. Субсидиарность осуществления публичной власти (а именно закрепление публично-властного полномочия на том уровне, на котором оно может исполняться с наибольшей эффективностью).

2. Проблемы сбалансированности перераспределения полномочий 
(баланса развития региона и развития муниципалитета, прав населения субъекта РФ в целом и прав жителей муниципального образования,), в том числе проблема критериев для осуществления перераспределения полномочий (например, уровень расчётной бюджетной обеспеченности муниципальных образований).

3. Проблемы дефектов юридической техники (вкладывание нового смысла в устоявшиеся термины вносит элементы внутренней правовой дисгармонии в процесс нормативного регулирования в соответствующей области).

\section{Раздел 4. Наделение органов местного самоуправления отдельными государственными полномочиями}

Понятие «наделение органов местного самоуправления отдельными государственными полномочиями» ставит исследователей перед целым рядом вопросов. Необходимо выяснить, являются ли определяющими для полномочий в данном случае органы, осуществляющие данные полномочия, или их природа, содержание прав и обязанностей, порождённых наличием данных полномочий.

Согласно части 2 статьи 132 Конституции Российской Федерации органы местного самоуправления могут наделяться отдельными государственными полномочиями. При этом Конституция Российской Федерации не содержит определения указанного понятия. В Федеральном законе № 154Ф3 также не было дано определения понятия «отдельные государственные полномочия, которыми наделены либо могут наделяться органы местного самоуправления».

Статья 19 Федерального закона № 131-Ф3 даёт определение понятия «отдельные государственные полномочия». Согласно части 1 указанной статьи, отдельными государственными полномочиями, передаваемыми для осуществления органам местного самоуправления, являются полномочия органов местного самоуправления, установленные федеральными законами и законами субъектов Федерации, по вопросам, не отнесённым этим Законом к вопросам местного значения.

Отдельным вопросом является правомочность такого распоряжения перераспределёнными полномочиями, как наделение ими органов МСУ. Представляется правильной позиция, согласно которой правомочия субъекта Российской Федерации применительно к полномочиям, определяемых федеральными законами предусматривают не только исполнение таких полномочий, но и возможность их передачи.

Такой механизм позволяет органам государственной власти субъекта Российской Федерации осуществлять координацию исполнения органами местного самоуправления соответствующих полномочий, финансировать исполнение этих полномочий за счёт субвенций из бюджета субъекта Российской Федерации, обеспечить единообразие правового регулирования исполнения полномочий (особенно в тех случаях, когда полномочия являются особо значимыми с общественной (в том числе с антикоррупционной) точки зрения и объективно нуждаются в унификации регулирования. 


\section{ИНФОРМАЦИЯ ОБ АВТОРАХ}

Бальтников Вадим Владимирович - кандидат юридических наук, директор Центра исследований проблем территориального управления и самоуправления Московского государственного областного университета;

e-mail: vv.balytnikov@mgou.ru

Глухов Вадим Витальевич - заместитель директора Центра исследований проблем территориального управления и самоуправления Московского государственного областного университета;

e-mail:vv.glukhov@mgou.ru

Михайлов Евгений Николаевич - заместитель директора Центра исследований проблем территориального управления и самоуправления Московского государственного областного университета;

e-mail: en.mikhailov@mgou.ru

Сергеев Алексей Аронович- доктор юридических наук, главный научный сотрудник Центра исследований проблем территориального управления и самоуправления Московского государственного областного университета;

e-mail: aa.sergeev@mgou.ru

Чертков Александр Николаевич - доктор юридических наук, главный научный сотрудник Центра исследований проблем территориального управления и самоуправления Московского государственного областного университета;

e-mail: an.chertkov@mgou.ru

Штукин Владислав Владимирович - кандидат юридических наук, старший научный сотрудник Центра исследований проблем территориального управления и самоуправления Московского государственного областного университета;

e-mail:vv.shtukin@mgou.ru

\section{INFORMATION ABOUT THE AUTHORS}

Vadim V. Balytnikov - PhD in Law, Director of Moscow Region State University Centre for Territorial Government and Self-Government Research;

e-mail: vv.balytnikov@mgou.ru

Vadim V. Glukhov - Deputy Director of Moscow Region State University Centre for Territorial Government and Self-Government Research;

e-mail:vv.glukhov@mgou.ru

Evgeny N. Mikhailov - Deputy Director of Moscow Region State University Centre for Territorial Government and Self-Government Research;

e-mail:en.mikhailov@mgou.ru

Aleksey A. Sergeev - Doctor of Law, Chief Researcher of Moscow Region State University Centre for Territorial Government and Self-Government Research;

e-mail: aa.sergeev@mgou.ru 
Alexander N. Chertkov - Doctor of Law, Chief Researcher of Moscow Region State University Centre for Territorial Government and Self-Government Research;

e-mail: an.chertkov@mgou.ru

Vladislav V. Shtukin - PhD in Law, Senior Researcher of Moscow Region State University Centre for Territorial Government and Self-Government Research;

e-mail:vv.shtukin@mgou.ru 